University of Nebraska - Lincoln

DigitalCommons@University of Nebraska - Lincoln

Faculty Publications from Nebraska Center for Research on Children, Youth, Families, and Schools
Children, Youth, Families \& Schools, Nebraska Center for Research on

2007

\title{
Teacher education, motivation, compensation, workplace support, and links to quality of center-based child care and teachers' intention to stay in the early childhood profession
}

\author{
Julia C. Torquati \\ University of Nebraska-Lincoln, jtorquati1@unl.edu \\ Helen Raikes \\ University of Nebraska-Lincoln, hraikes2@unl.edu \\ Catherine Huddleston-Casas \\ University of Nebraska - Lincoln, chuddleston-casas2@unl.edu
}

Follow this and additional works at: https://digitalcommons.unl.edu/cyfsfacpub

Part of the Pre-Elementary, Early Childhood, Kindergarten Teacher Education Commons

Torquati, Julia C.; Raikes, Helen; and Huddleston-Casas, Catherine, "Teacher education, motivation, compensation, workplace support, and links to quality of center-based child care and teachers' intention to stay in the early childhood profession" (2007). Faculty Publications from Nebraska Center for Research on Children, Youth, Families, and Schools. 23.

https://digitalcommons.unl.edu/cyfsfacpub/23

This Article is brought to you for free and open access by the Children, Youth, Families \& Schools, Nebraska Center for Research on at DigitalCommons@University of Nebraska - Lincoln. It has been accepted for inclusion in Faculty Publications from Nebraska Center for Research on Children, Youth, Families, and Schools by an authorized administrator of DigitalCommons@University of Nebraska - Lincoln. 
Published in Early Childhood Research Quarterly 22:2 (2nd Quarter 2007), pp. 261-275; doi: 10.1016/j.ecresq.2007.03.004

Copyright (C) 2007 Elsevier Inc. Used by permission.

Submitted March 7, 2007; revised March 20, 2007; accepted March 21, 2007; published online April $23,2007$.

\title{
Teacher education, motivation, compensation, workplace support, and links to quality of center-based child care and teachers' intention to stay in the early childhood profession
}

\author{
Julia C. Torquati, Helen Raikes, and Catherine A. Huddleston-Casas \\ University of Nebraska-Lincoln, Lincoln, NE, USA \\ Corresponding author - J. C. Torquati, 135 Mabel Lee Hall, University of Nebraska-Lincoln, \\ Lincoln, NE 68688-0236, USA; tel 402 472-1674, email jtorquati1@unl.edu
}

\begin{abstract}
The purposes of this study were to present a conceptual model for selection into the early childhood profession and to test the model using contemporaneous assessments. A stratified random sample of center-based child care providers in 4 Midwestern states $(n=964)$ participated in a telephone interview, and 223 were also assessed with the Early Childhood Environment Rating Scale-Revised or the Infant-Toddler Environment Rating Scale to rate global observed quality, and the Caregiver Interaction Scale to rate interactional quality. When the model was tested with infant-toddler and preschool teachers combined, having a Child Development Associate (CDA) predicted global observed quality, education years and child development coursework predicted compensation, and compensation predicted observed quality. When the model was tested separately for infant-toddler teachers, years of education and child development coursework predicted compensation, but none of the education variables predicted observed quality and compensation did not predict observed quality. For preschool teachers, years of education predicted compensation and having a CDA predicted observed quality, but compensation did not predict observed quality. For all of the models, only motivations for child care work predicted intention to stay in the profession. No variables in the structural equation models predicted interactional quality.
\end{abstract}

Keywords: child care quality, compensation, teacher education

\section{Introduction}

A great deal of research has documented associations among education, motivation, and compensation of early childhood professionals and the quality of care and education they provide (Ghazvini \& Mullis, 2002; Phillips, Mekos, Scarr, McCartney, \& Abbott-Shim, 2000; Sachs, 2000; Whitebook, Howes, \& Phillips, 1990). Better compen-

This research was supported by grant 90-YE0011/01 from the U.S. Department of Health and Human Services Administration on Children, Youth, and Families, Child Care Bureau; and the Ewing Marion Kauffman Foundation, Kansas City, Missouri. The contents are solely the responsibility of the authors and do not represent the official views of the funding agency, nor does publication in any way constitute an endorsement by the funding agency. Research reported here was conducted in collaboration with the Midwest Child Care Research Consortium. Principal investigators include Susan Hegland and Carla Peterson, Iowa State University; Jane Atwater and Jean Ann Summers, University of Kansas; Kathy Thornburg, University of Missouri; Carolyn Edwards and Julia Torquati, University of Nebraska. Helen Raikes and Brian Wilcox, University of Nebraska, were project directors. 
sated professionals provide higher quality care and education generally, and characteristics professionals bring to the workplace such as education and motivation also positively impact program quality (Barnett, 2002; Phillips, Howes, \& Whitebook, 1991; Whitebook, 2003). However, attracting and retaining highly qualified professionals into the early care and education field remains a challenge (Olson, 2002). Estimates of provider turnover rates range from 26 to $46 \%$ annually (Whitebook, Phillips, \& Howes, 1993). The purpose of this paper is to propose and begin to test a model that focuses on understanding career pathways of early childhood professionals, including the dynamics of selection into the field and into programs of varying quality, as well as retention or intentions to leave. It is important to understand career choices and pathways of early childhood professionals in order to attract and retain the most qualified individuals to provide early care and education, which is linked to maximizing potential and well-being of young children (Zaslow \& Martinez-Beck, 2006).

\subsection{Compensation, teacher qualifications, and quality of care and education}

Early childhood educators are among the most poorly paid professionals (Center for the Child Care Workforce, 2002; Nelson, 2001; Whitebook, Howes, \& Phillips, 1998). Individuals providing care and education for children ages 0-5 earn less than kindergarten or elementary school teachers, on average (Fuller \& Strath, 2001). Low wages are detrimental to both early childhood professionals, who often earn poverty level wages, and to the children for whom they care. Low wages are associated with higher staff turnover, which is known to be harmful to the development of children (Phillips et al., 1991; Whitebook, 2002). Furthermore, early childhood professionals who earn higher wages provide higher quality care (Ghazvini \& Mullis, 2002; Phillips et al., 2000; Sachs, 2000; Whitebook et al., 1990).

Studies of child care quality indicate that on the whole, a minority of child care programs in the U.S. meet "good" quality standards that are associated with positive developmental outcomes for children (Cost Quality Outcomes Study Team, 1995; Helburn \& Howes, 1996; Kontos, Howes, Shinn, \& Galinsky, 1995; Love, Schochet, \& Mechstrom, 1996; NICHD Early Child Care Research Network, 2000). Research shows generally that better educated professionals provide higher quality care and education (Blau, 2000; Burchinal, Cryer, Clifford, \& Howes, 2002; Howes, Whitebook, \& Phillips, 1992; NICHD, 2002; Sachs, 2000; Whitebook, 2003; Whitebook et al., 1990). The same is not true for years of experience, however; having more experience in the absence of further education does not necessarily lead to higher quality care.

\subsection{Compensation of early childhood educators}

It is estimated that parent fees cover less than half the full cost of child care, and that an estimated $20 \%$ of the true cost of child care is carried by early childhood professionals who earn less in the child care sector than they could earn elsewhere (Helburn, 1995). Child care wages often fall below poverty guidelines; in fact, one-third of early childhood teachers in Missouri reported that they had to rely on one or more forms of public assistance (Center for Family Policy Research, 2002). Whitebook and Sakai (2004) reported that teachers in their study earned, on an average, two-thirds of a self-sufficiency wage. The self-sufficiency standard is defined as how much income is needed in a given market to adequately meet basic needs without public or private assistance (Pearce \& Brooks, 2002). If compensation cannot meet self-sufficiency living expenses, early childhood teachers may be compelled to leave the profession.

\subsection{The role of compensation in occupational selection, intention to be in the profession, and turnover}

We consulted research addressing the choice of early childhood education as a profession in order to examine potential processes of selection into and out of the field. A study of first year early education students reported greater dissatisfaction with practicum experiences in child care centers than kindergartens, and only $9 \%$ intended to work in child care after graduation while $43 \%$ preferred to work in kindergartens (39\% reported that they would be satisfied in either setting) (Harding, 1991). Perceived disadvantages of child care cited by students included the low level of pay, length of work year, and hours of work. Thus, almost half of the sample selected themselves out of child care prior to beginning their careers, and both compensation and workload were primary factors cited for their decisions.

Drawing on investigations of turnover in a variety of occupations, Manlove and Guzell (1997) posited that "the extremely low wages in child care impact quality primarily by preventing qualified and committed individuals from considering child care work in the first place ..." (p. 148). Stremmel (1991) found that early childhood profes- 
sionals' commitment, satisfaction with pay and opportunities for promotion, and perceived availability of alternative employment significantly predicted intention to leave the field. Moreover, low satisfaction with pay was the most important work-related factor cited as influencing desire to leave. However, Stremmel (1991) pointed out that going back to school, relocating, or other personal factors also influence the decision to leave.

Selection into and out of public school teaching is qualitatively different from child care in several ways, but research on these dynamics may still inform our efforts to understand the same processes in child care. Some of the differences salient to this investigation include: state mandated education and credential standards; higher starting wage and pre-specified wage structure based on years of experience and additional education; and a shorter work year in comparison to child care centers. Two longitudinal studies followed all first year public school teachers in two states over 10 years, and results of both studies indicate that teachers who are better compensated stay longer in teaching (Murnane and Olsen, 1989, 1990).

\subsection{Opportunity costs and retention in the education profession}

Opportunity costs also influence selection out of the profession. Teachers with a specialty that is marketable outside the teaching sector have shorter median stays in the teaching profession (Murnane \& Olsen, 1989), and those who have higher opportunity costs - who could earn higher wages in the non-teaching sector-leave teaching sooner than those with lower opportunity costs (Murnane \& Olsen, 1990). Teachers who perceive that they have alternatives outside of the profession are more than five and a half times more likely to leave the profession within 12 months in comparison to those who do not perceive alternatives, all else being equal (Manlove \& Guzell, 1997). Teachers with greater academic ability leave the profession sooner, indicating that opportunities in the non-teaching sector are important incentives to selection out of teaching (Cleveland \& Hyatt, 2002; Murnane \& Olsen, 1989; Stinebrickner, 2001).

Perceived opportunities for advancement can also predict retention in the teaching profession. Many teachers anticipate moving into administrative positions, which offer 20-25\% higher salaries than teaching positions. When district salaries are higher for administrator positions, teachers are less likely to leave their district. However, if administrator salaries rise in nearby districts, teachers are more likely to leave (Brewer, 1996). It may be similarly important to consider opportunities for advancement into administrative positions in child care as a factor contributing to retention.

\subsection{Model building and hypotheses}

We propose a model for considering processes of selection into the early childhood profession, supports for staying in the profession, and dynamics of decisions to leave the profession. We conceptualize this decision-making process using the resource management framework within a human ecological perspective as first proposed by Danes and Rettig (1995). From this perspective, decisions to select into the early childhood profession and to stay in or to leave the profession occur at the interface of the decision-maker and the environment. Consequently, factors such as the characteristics of the decision-maker, here the early childhood professional, as well as characteristics of the environment such as intrinsic and extrinsic work supports will impact the decision to stay or leave the profession. Of interest here is how the decision-making process impacts the quality of care provided within the environment under study. These processes are examined by simultaneously considering characteristics of professionals and intrinsic and extrinsic work supports as predictors of global observed quality, interactional quality, and intention to stay in the profession.

\subsubsection{Exogenous variables: Education, motivations for child care work, and ratio}

Early childhood professionals bring characteristics such as education and motivations for child care work which can influence opportunities and choices pertaining to the kinds of programs in which they are ultimately employed. More highly educated professionals are more competitive in the market, and therefore presumably have more flexibility of choice when selecting programs in which to work. In order to test the selection process directly, providers would ideally be studied during their career preparation or while they are interviewing for positions; as noted above, many early childhood professionals select themselves out before entering the field. However, in the current study, we use concurrent data from providers to examine two resources they bring with them into the profession, education and motivation, as proxy selection factors. We hypothesize that teachers' education is associated with program quality in three ways: (1) better educated teachers are more likely to choose to work in a higher quality 


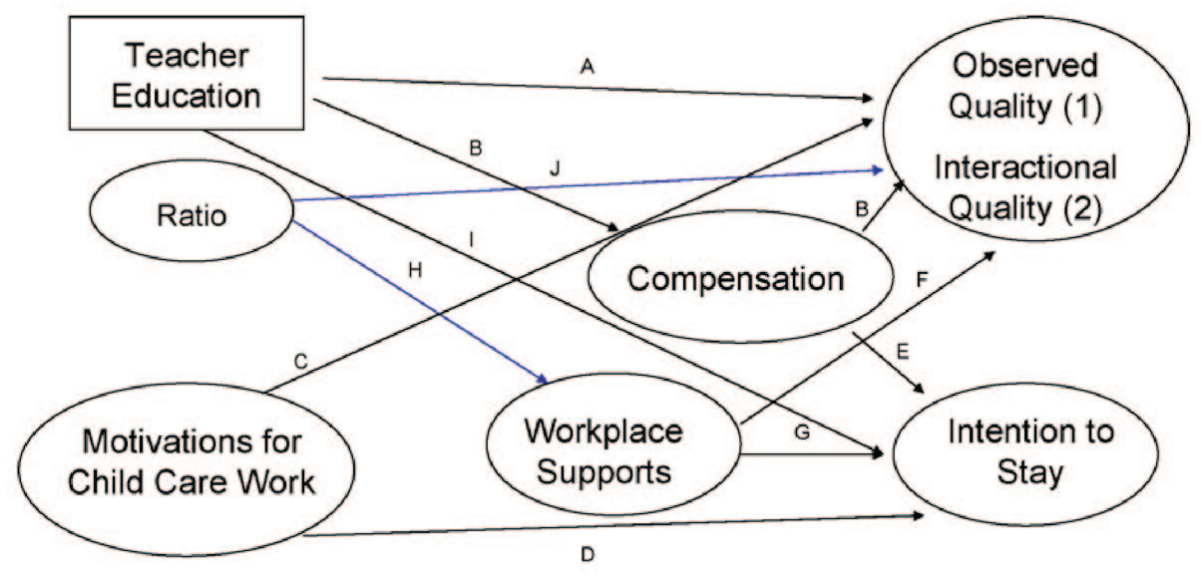

Figure 1. Proposed model predicting observed quality, interactional quality, and intention to stay in the profession.

program; (2) better educated teachers are more competitive in the market, so they are able to select programs that offer better compensation [and those programs are more likely to be higher quality (Whitebook et al., 1993)]; and (3) the knowledge and skills a better educated teacher brings to a program positively influences the quality of the program (Whitebook, 2003). These relationships are illustrated by both direct (A) and mediated (B) paths (see Figure 1). We expect a direct effect for education (path I) on our second outcome-intention to stay in the field. However, it is possible this effect will not be seen given literature from other fields showing teachers with higher opportunity costs may be early leavers or that effects for education on intention to stay could be mediated by other factors such as compensation (path E) (Murnane \& Olsen, 1990).

A second characteristic that early childhood professionals bring with them is their motivation for child care work. Employees in the field of early care and education vary in their intrinsic motivation to specifically work with young children (Kontos, Hsu, \& Dunn, 1994). Intrinsic work motivation, or the extent to which a professional is motivated to perform well in their job according to specific content, task characteristics, perceived significance of the work, and autonomy, are important in predicting intention to stay in a profession (Houkes, Janssen, de Jonge, \& Nijhuis, 2001). Therefore, we hypothesize that: (1) motivations for child care work are positively associated with observed quality (Galinsky, Howes, Kontos, \& Shinn, 1994) (path C) and (2) motivations for child care work influence commitment to the profession, defined for this study as intention to stay (path D).

Staff-child ratio is included as a predictor of observed quality and of workplace supports. Staff-child ratio has consistently been associated with more positive teacher-child interactions and overall quality (Helburn \& Howes, 1996; NICHD Early Child Care Research Network, 2000; Whitebook et al., 1990). The influence of staff-child ratio is represented in the model by path $\mathrm{H}$ to workplace supports and path $\mathrm{J}$ to observed quality.

\subsubsection{Mediating variables: Compensation and workplace supports}

Our model includes two mediating variables: compensation and workplace supports. According to microeconomic theory and supporting evidence, compensation and opportunity costs influence career decisions (Brewer, 1996; Murnane \& Olsen, 1990). Compensation influences selection into the field (Stremmel, 1991) and selection of specific employment (Murnane \& Olsen, 1990). All else being equal, individuals will select employment that offers the best "extrinsic" and "intrinsic" benefits (Brewer, 1996; Murnane \& Olsen, 1990). Extrinsic benefits are those that are not directly related to the work environment or nature of the work, but support individuals outside of the workplace, such as compensation. We operationalized compensation for the present study to include wages and benefits, and hypothesize that compensation is positively associated with observed quality (path B) (Ghazvini \& Mullis, 2002; Phillips et al., 2000; Sachs, 2000; Whitebook et al., 1990) and intention to stay in the profession (path E).

Intrinsic benefits are characteristics of the work and workplace that influence satisfaction with work tasks, workload, and the nature of the work. For the present study, an intrinsic construct is proposed that includes characteristics of the work environment that can influence the ability of professionals to do their work well, and satisfaction with the workplace. We have labeled this construct "workplace supports", and it includes three characteristics: (1) professional supports; (2) physical/material resources; and (3) absence of work overload. We hypothesize that workplace supports have independent and positive effects on both observed quality (path F) and intention to stay (path G). 
Although extrinsic and intrinsic characteristics of the workplace may be correlated, we hypothesize that these operate independently in predicting observed quality and intention to stay. For example, a professional may enjoy their job and be well supported in the workplace, but not be compensated sufficiently to support themselves or their family. Conversely, an individual might not enjoy their job, but perceive that they do not have other alternatives, so stay even though they are not well compensated. Therefore, we will test the model separately for teachers of infant/toddlers and preschool aged children, because preschool teachers have more education and are better compensated, on average, than teachers of infants and toddlers (Raikes et al., 2003), and therefore may have more choice in both occupation and work setting.

\subsubsection{Endogenous variables: Observed quality and intention to stay in the profession}

Observed program quality is an important endogenous variable, because the goal of attracting and retaining qualified individuals into the field of early care and education is to support children's development. Observed quality was assessed in two distinct ways: (1) global quality, which encompasses multiple dimensions of health and safety, learning activities, etc., and (2) interactional quality, which specifically focuses on teacher-child interactions.

Individuals who state they intend to leave a profession are more than four and a half times more likely to leave within 12 months than those who do not, holding all other predictors of turnover constant (Manlove \& Guzell, 1997). Therefore, intention to leave can be reliable predictor of actually leaving a profession. Because we are interested in predicting retention in the profession, we use two indicators to assess the probability of staying in the profession: (1) how long teachers actually plan to stay in the profession; and (2) whether they would do other work if they could (a positive response indicating intention to leave).

Family child care homes differ substantially from child care centers on dimensions of workplace supports. For example, self-employed family child care providers do not receive employer-paid benefits, and family child care providers typically do not have directors or co-workers who help to shape the nature of the working environment. Therefore, the model will be tested with center-based providers only.

In summary, three exogenous variables represent: (1) providers' education, (2) providers' motivations for child care work, or the degree to which they intentionally choose the profession, and (3) structural support for quality (ratio). Two mediating variables represent: (1) "extrinsic" characteristics of the workplace, operationalized for this study as teacher compensation, and (2) "intrinsic" characteristics of the workplace, operationalized as professional supports, physical and material resources, and absence of work overload. Two endogenous variables, (1) program quality and (2) intention to stay in the profession represent the output of the model.

\section{Procedures and methods}

\subsection{Overview of methods}

The Midwest Child Care Research Consortium was organized in 1999 to conduct a comprehensive study of child care quality in Iowa, Kansas, Nebraska, and Missouri. The Consortium included University researchers, child care licensing personnel and representatives from departments of education and health and human services in each state, and researchers from the Gallup Organization.

A stratified random sample was drawn from state-level child care licensing and subsidy files that identify providers and programs providing full-day child care. The stratification criteria included: state; subsidy/non-subsidy; center-based programs for infants/toddlers and preschool aged children; licensed family homes; registered family homes; license exempt homes; and Early Head Start/Head Start partners. Respondents were randomly selected until the strata were complete and they were contacted by telephone between April and August 2001. The total survey sample was 2022. Nine hundred and sixty-four providers worked in child care centers, and these comprise the sample of analysis for this paper. All of the programs were full-day full year child care centers. A subset of 223 center-based providers participated in program observations (122 infant/toddler providers and 101 preschool providers). Approximately half (105) were engaged in partnerships to follow the Head Start Performance Standards, while caring for Head Start or Early Head Start children in their child care settings. None of these partner centers were Head Start programs themselves. Providers were selected for observation based on the stratification criteria. 


\subsection{Procedures}

The Gallup Organization drew the stratified random sample and contacted providers by telephone. A seven call call-back method was used to ensure the integrity of the random design. The survey response rate for eligible center-based respondents was $99 \%$. The person who answered the telephone was informed about the study and was asked to identify a full-time teacher using a first letter of the teacher's name that was randomly identified by the Gallup interviewer, or to respond to the survey if they were the only provider at the number. In order to ensure that all participants were full-time teachers, selected teacher was asked: "Are you a regular, full-time teacher or child care provider at the center?" All participants in the sample responded affirmatively. All providers who indicated their willingness to be re-contacted $(95 \%)$ were put on a list to be drawn for follow-up observations. Researchers in each state followed the stratification procedures to draw the observation sample and contacted participants by telephone to invite them to participate in the observation phase of the study. Across the four states, response rates among those who were called for observations ranged from 48 to $59 \%$. Teachers received a $\$ 20$ gift certificate in appreciation of their participation.

\subsection{Sample}

Ninety-nine percent of providers who completed the survey were female and the mean age of center-based providers was 35 years (S.D. $=12.0)$. Slightly more than one-tenth $(12 \% ; n=120)$ of providers reported 10 or more years of experience; approximately one-fifth $(19 \% ; n=187)$ reported $5-10$ years of experience; $15 \%(n=141)$ reported $3-5$ years of experience; 29.4\% $(n=283)$ reported 1-3 years of experience; and $24 \%(n=233)$ had less than 1 year of experience. The majority of participants $(83 \% ; n=802)$ were Caucasian, $8.4 \%(n=81)$ were African-American, $5.7 \%(n$ $=55)$ Hispanic, and $1.2 \%(n=12)$ were American Indian. The majority of participants $(72 \% ; n=695)$ were parents, and almost half $(45 \% ; n=380)$ cared for their own children in the child care setting in which they worked.

\subsection{Measures}

\subsubsection{Telephone survey}

Child care providers completed a 12.5 min survey about themselves and their workplaces. Analysis of demographic questions, motivations for child care work, supportiveness of the work environment, teacher compensation, and intention to stay in the field are included in this paper.

\subsubsection{Education}

Teachers were asked to select their highest level of education from an array that ranged from less than high school to graduate school courses or degree, and then were asked, "Was your major area of training or education child development-related?" Participants were also asked, "Do you currently hold any of the following certificates including teaching certificate from your state, CDA, Montessori, or Parents as Teachers?" Almost one-fourth of participants $(22.7 \% ; n=219)$ indicated that a high school diploma was their highest level of education, $17.7 \%(n=169)$ had a Child Development Associate (CDA) credential, 16.5\% $(n=159)$ had a bachelor's degree (any major), and 6\% $(n=$ 56) reported more than a bachelor's degree. Eighteen percent $(n=172)$ of center-based providers had a teaching certificate from their state. Years of education ranged from 11 to 17 (mean = 13.6; S.D. =1.6).

\subsubsection{Motivations for child care work}

Motivations for child care work were assessed by three questions (Kontos et al., 1994). Providers were asked to rate on a scale from (1) "definitely does not represent" to (5) "definitely represents" how well each of the following questions describes their motivation for child care work: (1) "my career or profession" (mean = 4.4; S.D. = 1.1); (2) "a stepping stone to a related career or profession" (mean = 3.5; S.D. = 1.5); and (3) "a personal calling" (mean = 4.5; S.D. $=.8$ ). The last question was designed specifically for this study based on qualitative findings from another study of provider motivation (Buell, Pfister, \& Game-McCormick, 2002).

\subsubsection{Supportiveness of the work environment}

Three dimensions of the work environment were assessed. First, the Gallup Q12 ${ }^{\mathrm{TM}}$ is a measure of workplace climate used in a wide variety of organizations and industries, and was used to assess professional supports (Buckingham \& Coffman, 1999). Providers rated the degree to which each of 12 questions describes their current work 
situation on a scale from (1) "strongly agree" to (5) "strongly disagree". A total score was derived by computing the mean of all items $(a=.82$; mean $=4.49$; S.D. $=.5)$. Sample items include: "At work, I have the opportunity to do what I do best every day"; "My supervisor, or someone at work, seems to care about me as a person"; "I have the materials and equipment I need to do my work right"; and "In the last six months, someone at work has talked to me about my progress".

Second, providers were asked to rate the extent to which their workplace has good indoor spaces, good outdoor spaces, and whether children have daily access to a good supply of toys on a scale from (1) strongly disagree to (5) strongly agree, in order to assess material supports for their work. Finally, providers were asked to rate the statement, "At least twice a week, you are left alone with too many children", on a scale from (1) strongly disagree to (5) strongly agree. This item was recoded so that a higher score would indicate that they are not left alone with too many children, so that this item would be an indicator of less workplace stress or overload.

\subsubsection{Teacher compensation}

As a group, $14.7 \%(n=142)$ earned $\$ 9999$ or less per year, $43.4 \%(n=399)$ earned between $\$ 10,000$ and 14,999 per year, 23.6\% $(n=217)$ earned between $\$ 15,000$ and 19,999 per year, $10.2 \%(n=94)$ earned between $\$ 20,000$ and 24,999 per year, 3.9\% $(n=38)$ earned between $\$ 25,000$ and 29,999 per year, and 3.5\% $(n=30)$ earned $\$ 30,000$ or more per year. Center-based preschool providers earned an average of $\$ 16,330$ annually, and center-based infant providers earned $\$ 14,470$. Gallup created a continuous variable, by centering each category and using survey averages for the lowest and highest category, following standard methodology for this conversion.

Center-based providers were asked if they received any benefits from their ECE employment, and 75\% $(n=$ 721) responded affirmatively. Providers were also asked which of the following benefits they receive from child care employment: health insurance for yourself; health insurance for your family; paid vacation days; paid sick days; paid days to attend professional meetings; reduced or no tuition for your own children to receive child care; and retirement benefits. Thirty-nine percent $(n=375)$ of center-based providers received health insurance for themselves, and 30\% $(n=290)$ received health insurance for their family. Two-third of providers $(67.9 \% ; n=$ $655)$ received paid vacation days, and $56 \%(n=541)$ received paid sick days. About half $(53 \% ; n=513)$ received paid days to attend professional meetings, and $62.4 \%(n=439)$ received reduced or no tuition for their own children. A little more than one-fourth $(26 \% ; n=252)$ of providers received retirement benefits. A composite benefits score ranging from 0 to 7 was computed as a sum of the total number of benefits reported by each participant $($ mean $=4.3$; S.D. $=1.7)$.

\subsubsection{Intention to stay in the field of early care and education}

Two questions assessed providers' intent to stay in the field of early care and education. First, providers were asked, "How much longer do you plan to be a child care provider?" The response choices were: (1) less than 6 months $(3.2 \% ; n=31)$; (2) 6 months to less than 1 year $(3.9 \% ; n=37)$; (3) 1 year to less than 2 years $(7.6 \% ; n=73)$; (4) 2 years to less than 5 years $(21.2 \% ; n=203)$; and $(5) 5$ years or longer $(64.1 \% ; n=614)$. The second question assessing intention to stay in the field was: "If you could do so now, would you choose work other than child care?" The response choices for this question were: $(1)$ yes $(16.2 \% ; n=155)$ and $(2)$ no $(83.8 \% ; n=802)$. Respondents indicating that they would not choose other work are considered to be more committed to staying in the profession. Overall, participants reported high commitment to the early childhood education profession.

\subsubsection{Observed program quality}

The Infant/Toddler Environment Rating Scale (ITERS; Harms \& Cryer, 1990) and the Early Childhood Environment Rating Scale-Revised (ECERS-R; Harms, Clifford, \& Cryer, 1998) were used to assess observed program quality. Trained data collectors conducted an observation of at least $2 \mathrm{~h}$ to complete each assessment. Teachers were interviewed regarding items that were not observed at the time (for example, nap time procedures if the observation was done early in the day). The ITERS and ECERS-R provide industry standard measures of child care quality and a score of 5-7 is considered to be "good" to "excellent" quality, a score less than 3 is considered "poor" quality, and the zone between " 3 " and " 5 " is defined as mediocre or minimal quality.

The ECERS-R is a 43-item scale with seven subscales: space and furnishings, personal care, language-reasoning, activities, interaction, program structure, and provisions for parents and staff. The ITERS is a similar instrument with 35 items and seven subscales: furnishings and display for children, personal care routines, listening and talking, learning activities, interaction, program structure, and adult needs. Descriptive statistics and Cronbach's alpha coefficients for each subscale and total scale scores for this sample are included in Table 1. The average total score 
Table 1. Descriptive statistics and reliability of environment rating scales

\begin{tabular}{lllll}
\hline \multirow{2}{*}{ Subscale } & \multicolumn{2}{l}{ Infant-toddler (ITERS) } & & \multicolumn{2}{l}{ Preschool (ECERS-R) } \\
\cline { 2 - 3 } & Mean (S.D.) & Reliability & Mean (S.D.) & Reliability \\
\hline Space/furnishings & $4.46(1.23)$ & .69 & $4.61(1.13)$ & .74 \\
Personal care & $4.3(1.26)$ & .74 & $4.70(1.36)$ & .70 \\
Language & $4.29(1.84)$ & .65 & $4.43(1.52)$ & .83 \\
Learning activities & $3.84(1.28)$ & .80 & $3.56(1.24)$ & $.87(1.56)$ \\
Social interaction & $4.65(1.17)$ & .73 & $4.56(1.68)$ & .85 \\
Program structure & $4.85(1.48)$ & .64 & $4.64(1.25)$ & .82 \\
Parents and staff & $3.66(1.39)$ & .72 & $4.43(1.12)$ \\
Total score & $4.25(1.04)$ & .93 & & .92 \\
\hline
\end{tabular}

Reliability estimated by Cronbach's alpha coefficient.

for each subscale was designated as the Environment Rating Scale Average (ERS), in order to predict observed quality of center-based care for both infants/toddlers and preschool aged children. Subscale scores were used to create the latent variable for quality.

\subsubsection{Interactional quality}

Interactional quality was measured by the Arnett Caregiver Interaction Scale (Arnett, 1989) which includes 26 items measuring 3 qualities of interaction: warmth (mean $=3.1$; S.D. $=.7 ; a=.94$ ); punitive (mean = 1.2; S.D. = .4; $a=.85$ ); and detachment (mean $=1.3 ;$ S.D. $=.5 ; a=.77$ ). Observers rated each item on a four-point scale ranging from 1 ("not at all true") to 4 ("very much true"). All subscales demonstrated good reliability in this sample.

\subsubsection{Staff-child ratio}

Staff-child ratio was computed by dividing the number of staff present during the observation by the number of children present during the observation. Staff-child ratio ranged from .08 to 1.00 (mean = .27; S.D. = .15).

\subsubsection{Inter-rater reliability}

Reliability in observations for the environment rating scales (ITERS, ECERS-R) and the Caregiver Interaction Scale was obtained across states by having "gold standard" observers from each state meet and establish minimum reliability with each other, defined as $85 \%$ agreement within one point. Reliability was established within states by training all observers with the "gold standard" observers to a level of $85 \%$ within one point. Paired observations were conducted every 10 observations to maintain reliability.

\section{Results}

Structural equation models testing the significance of teacher education, compensation, workplace supports, and teacher motivations for child care work predicting global observed quality, interactional quality, and intention to stay in the profession are presented. The models are tested for the whole sample, and then tested separately for teachers of infants/toddlers and teachers of preschool aged children.

\subsection{Structural models}

Latent constructs were built with multiple indicators for each variable, and the latent construct represents the shared variance among the indicators (see Figure 2). The variable teacher education is the only exception to this procedure, because the indicators (CDA, years of education, child development coursework, teaching certificate) define the variable, rather than being caused by a latent construct. Therefore, the teacher education indicators are treated as observed exogenous variables.

Teacher education was defined by years of education, CDA, child development coursework or training, and teaching certificate. Compensation was defined by total number of benefits and income from child care work. Moti- 


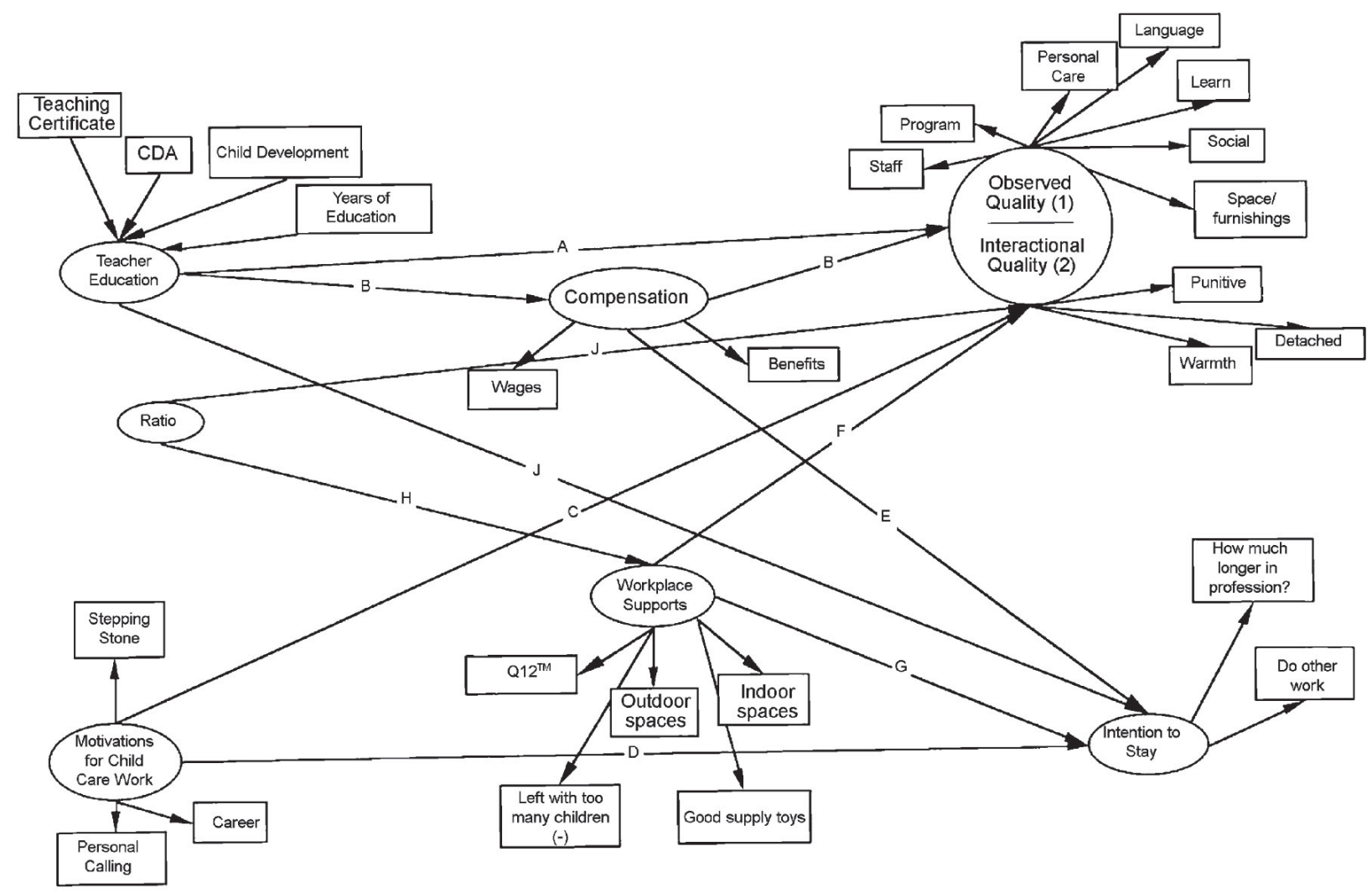

Figure 2. Measurement models.

vations for child care work was defined by three items assessing teachers' motivations for child care work (career/ profession, stepping stone, personal calling). Workplace supports were defined by the mean of the Gallup Q12 ${ }^{\mathrm{TM}}$, rated quality of indoor spaces and outdoor spaces, rated quality of toys, and whether teachers felt they were left alone with too many children during the past week (reverse coded). Global observed quality was defined by the subscale means of the ITERS or ECERS-R. Intention to stay was assessed by the number of years teachers intend to stay in the profession, and whether they would do other work if they could.

The statistical software program Mplus version 3.0 was used to test the structural models because it has the capacity to use numeric integration to incorporate categorical endogenous variables into the construction of latent variables. However, when numeric integration is invoked, fit indices are not computed. Therefore, only results of the significance tests for the paths are presented. The teacher education variable is defined by causal indicators, and is therefore an observed exogenous variable rather than a latent construct; to address this measurement issue, equivalent models were tested with each observed variable in sequence. Therefore, estimates for paths from observed teacher education variables to latent constructs are presented.

\subsubsection{Model 1: Predicting global observed quality and intention to stay}

The first model tested the significance of teacher education, compensation, workplace supports, and teacher motivations for child care work to predict global observed quality and intention to stay in the field. Four of the hypothesized paths were significant (Figure 3). The observed exogenous variables education years (standardized path coefficient $=.35$ ) and child development training (standardized path coefficient $=.25$ ) significantly predicted the latent construct teacher compensation. The observed exogenous variable CDA significantly predicted the latent construct global observed quality (standardized path coefficient $=.65$ ). Compensation significantly predicted global observed quality (standardized path coefficient $=.28$ ) and motivations for child care work significantly predicted intention to stay in the profession (standardized path coefficient $=.68$ ). The path from ratio to observed quality was not significant. The paths from workplace supports to quality, from teacher education to intention to stay in the profession, and from workplace supports to intention to stay in the profession were removed from the model because it would not converge when these paths were included. 


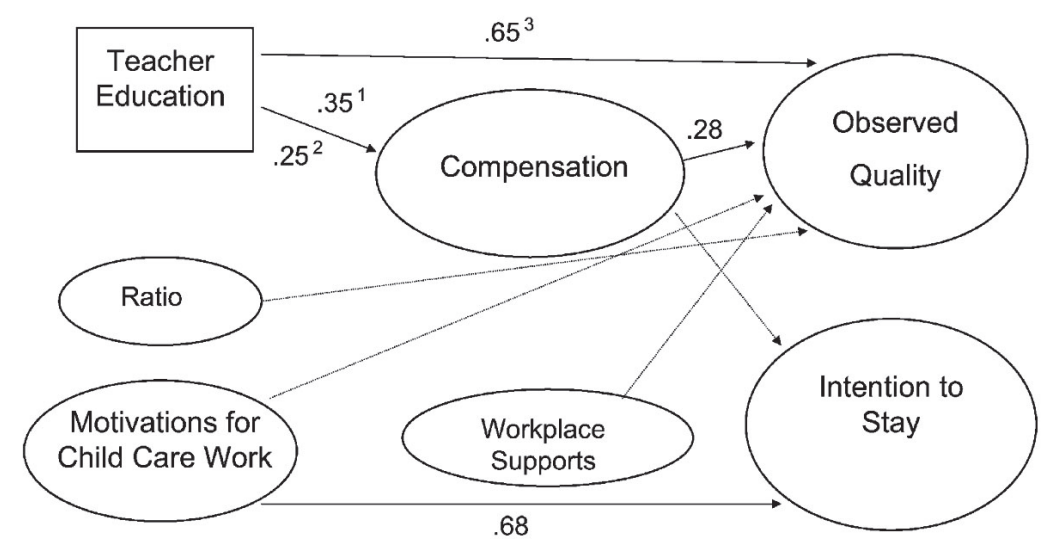

Figure 3. Predicting observed quality and intention to stay in the profession. Solid lines denote significant paths, and dashed lines denote non-significant paths. ${ }^{1}$ Years of education; ${ }^{2}$ Child development training; ${ }^{3}$ CDA.

\subsubsection{Model 2: Predicting interactional quality and intention to stay}

Two of the hypothesized paths were significant in the model predicting interactional quality and intention to stay (Figure 4). The observed exogenous variable education years significantly predicted the latent construct teacher compensation (standardized path coefficient $=.31$ ). Teacher motivations for child care work significantly predicted intention to stay in the profession (standardized path coefficient $=.67$ ). Model 2 would not converge when the ratio variable was included, so ratio was omitted. All remaining tested paths were non-significant.

\subsubsection{Teachers of infants and toddlers: Models 1 and 2}

Three of the hypothesized paths in the model predicting observed quality and intention to stay were significant (Figure 5). The observed exogenous variables education years (standardized path coefficient $=.38$ ) and child development training (standardized path coefficient $=.41$ ) both predicted compensation for teachers of infants and toddlers. Teacher motivations for child care work significantly predicted intention to stay in the profession (standardized path coefficient $=.80$ ). However, the only path that was significant in the model predicting interactional quality and intention to stay was the path from motivations for child care work to intention to stay in the profession (standardized path coefficient $=.80$ ).

\subsubsection{Teachers of preschool aged children: Models 1 and 2}

Three of the hypothesized paths in the model predicting observed quality and intention to stay in the profession were significant (Figure 6). Having a CDA predicted observed quality (standardized path coefficient $=.57$ ) and total years of education predicted compensation (standardized path coefficient $=.26$ ). Motivations for child care work predicted intention to stay in the profession (standardized path coefficient $=.56$ ). Two of the hypothesized paths in

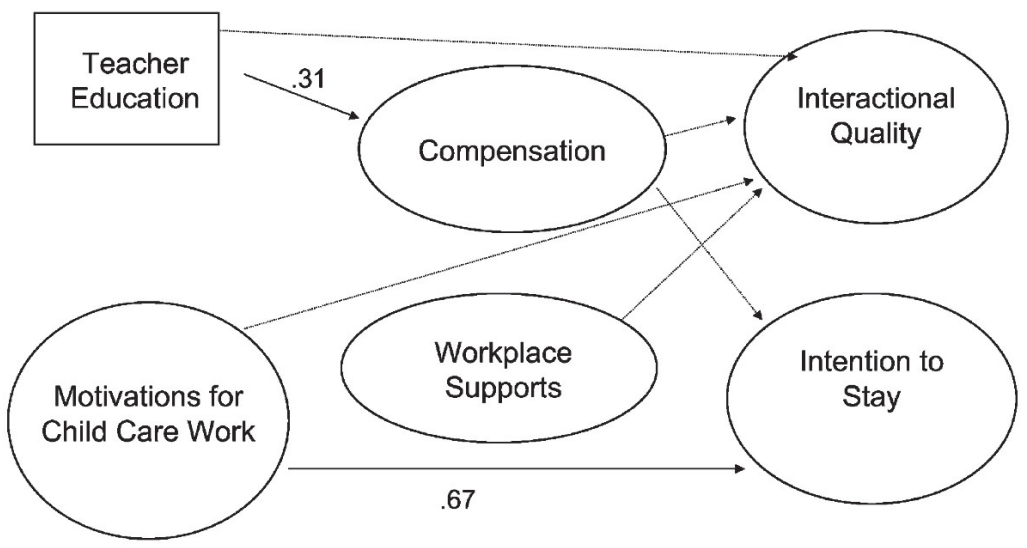

Figure 4. Predicting interactional quality and intention to stay in the profession. Solid lines denote significant paths, and dashed lines denote non-significant paths. 


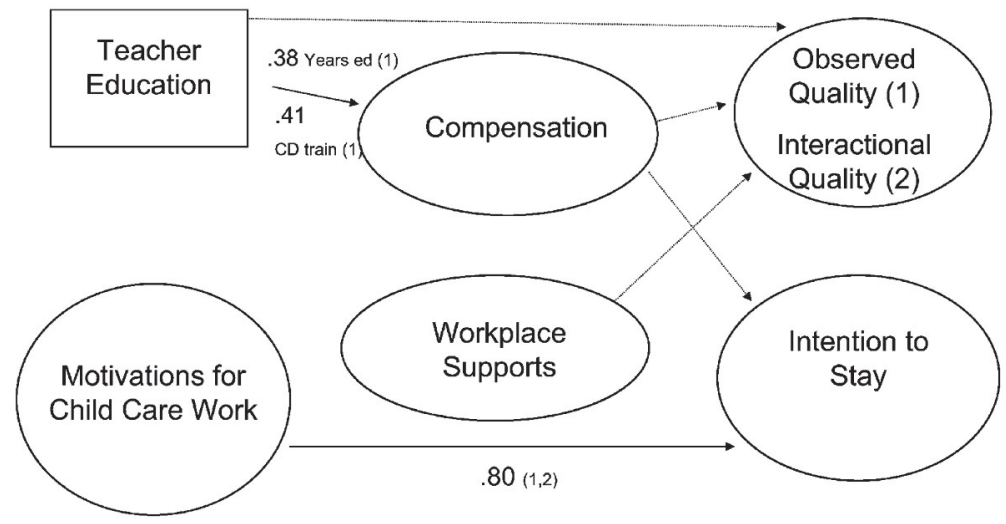

Figure 5. Predicting observed quality and intention to stay in the profession for infant-toddler teachers. Solid lines denote significant paths, and dashed lines denote non-significant paths. Numbers in parentheses indicate the model for which the path is significant.

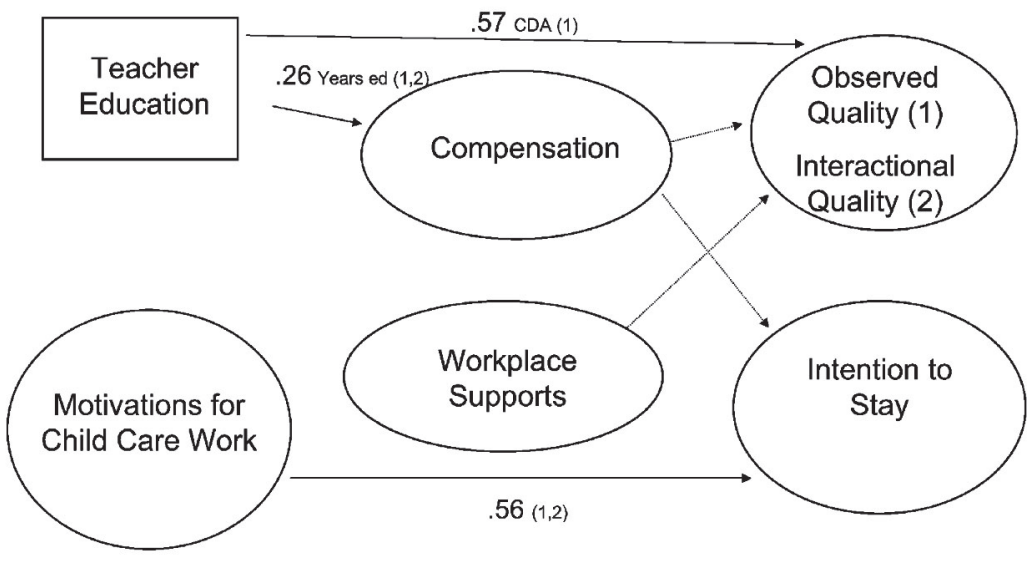

Figure 6. Predicting observed quality and intention to stay in the profession for teachers of preschool aged children. Solid lines denote significant paths, and dashed lines denote non-significant paths. Numbers in parentheses indicate the model for which the path is significant.

the model predicting interactional quality and intention to stay in the field were significant. Years of education predicted compensation (standardized path coefficient $=.26$ ) and motivations for child care work predicted intention to stay in the profession (standardized path coefficient $=.56$ ).

\section{Discussion}

This paper proposed and tested a model describing factors potentially influencing selection into and out of the early childhood profession, and implications of these dynamics for predicting global and interactional quality. We hypothesized that teacher characteristics, including education and motivations for child care work, play an important role in selection into the profession and into specific programs. We proposed that intrinsic and extrinsic characteristics of programs influence the selection process, such that teachers who are better qualified in regards to education or motivation have greater choice in selecting programs that offer better compensation and workplace supports. We hypothesized that the program characteristics that influence teacher choice also influence program quality and intention to stay in the profession. Finally, we proposed that teacher education and motivations for child care work directly influence program quality and intention to stay in the profession.

Hypotheses regarding teacher education and motivations for child care work were partially supported. For example, teacher motivation was a robust predictor of intention to stay in the field in all of the models tested; however, teacher motivation did not significantly predict observed or interactional quality. Conversely, teacher education (CDA) predicted observed quality, but the education variables did not predict intention to stay in the field in the SEM analyses. 
Years of education and in some cases, child development-specific coursework or training predicted better compensation (wages and benefits). It is possible that years of education are a concrete measure of qualification that employers use to make compensation decisions, however, years of education did not significantly predict observed quality in the structural equation models. Conversely, CDA significantly predicted quality, but not compensation. Having a teaching certificate was not associated with any indicators of quality. Child development-specific coursework or training and CDA preparation provide education specifically guided toward working with young children, and are usually informed by principles of developmentally appropriate practice (DAP), whereas teacher certification programs generally do not prepare professionals specifically to work with young children (ages $0-5)$ or emphasize developmentally appropriate practice for early childhood. Rather, the types of certificates respondents reported were more related to primary, secondary, or special education. Thus, these findings replicate others that indicate specific training for a skill set appropriate for very young children is effective in promoting global quality (Blau, 2000; Burchinal et al., 2002; Sachs, 2000; Whitebook, 2003; Whitebook et al., 1990; Whitebook \& Sakai, 2004).

Understanding predictors of interactional quality remains more elusive, however. None of the variables predicted interactional quality in the SEM analyses. It stands to reason that principles of DAP associated with curriculum and program structure, for instance, are more easily taught and learned than those associated with interactional quality. It may be more difficult, for example, to "teach" empathy, warmth, or patience, than it is to teach how to provide meaningful learning experiences through play.

Contrary to hypotheses, structural and intrinsic workplace supports did not predict interactional or global quality. Extrinsic supports actually demonstrated a more robust association with quality: compensation partially mediated the relation between teacher education and global quality when both infant/toddler and preschool teachers were included. This illustrates the non-independence of characteristics of providers and the programs in which they work: those who are better qualified are more competitive in the job market, and are likely to choose a position that offers maximal intrinsic and extrinsic benefits. Therefore, more highly qualified providers tend to choose programs that offer better compensation and that provide higher quality care, and provider and program characteristics work together to support quality. These findings replicate previous work documenting associations between child care wages and quality (Ghazvini \& Mullis, 2002; Phillips et al., 1991, 2000; Sachs, 2000; Whitebook et al., 1990) and underscores the importance of benefit receipt which may be an important extrinsic support for teachers.

Intrinsic supports were defined for this study as workplace characteristics, such as supportiveness of the workplace environment and having adequate space and material resources. It is possible that a different set of intrinsic supports, such as the psychological and emotional rewards of working with children would be a better predictor of intention to stay in the field. Findings from a small, qualitative study indicate that teachers who stay indicate that they do so because the work is emotionally and ideologically rewarding, and that they feel they are fulfilling a higher purpose by promoting positive social change (Murray, 2000).

Contrary to hypotheses, compensation did not predict intention to stay. This finding is inconsistent with previous research on satisfaction with pay for early childhood (Stremmel, 1991) and public school teachers (Murnane and Olsen, 1989, 1990]), and with actual pay and actual retention in early childhood programs (Whitebook \& Sakai, 2004). Low absolute wages and relatively low variability may have suppressed expected relations; however, Stremmel (1991) noted that other factors in addition to compensation contribute to decisions to leave the profession, such as family circumstances (e.g., moving for a spouse's employment opportunity, staying home to care for family members) and returning to school. Similarly, others have noted that women's career decisions may be less influenced by perceived opportunity costs than men's career decisions, and more influenced by family circumstances (Manlove \& Guzell, 1997; Murnane \& Olsen, 1989). Because the overwhelming majority of early childhood professionals are women and parents (Phillips et al., 1991; Raikes et al., 2003), the role of family circumstances in career decisions should be included in future research on selection and retention of early childhood professionals.

None of the models significantly predicted interactional quality. Interactional quality is important and warrants further investigation, because of its association with children's development (Birch \& Ladd, 1997; Howes, Hamilton, \& Matheson, 1994). If education is not substantially associated with providers' warmth, detachment, or punitiveness, how are providers with good interactional skills attracted, retained, and supported in the profession? One plausible predictor of interactional quality may be the teacher's state of mind with respect to attachment. Literature on parents' attachment and their interactions with young children has consistently demonstrated that secure parents are more warm and responsive than insecure parents (e.g., De Wolff \& Van IJzendoorn, 1997; Grossmann, Fremmer-Bombik, Rudolph, \& Grossmann, 1988; Jacobvitz, Morgan, Kretchmar, \& Morgan, 1991; Rholes, Simpson, \& Blakely, 1995; Van IJzendoorn, 1995), and at least one investigation has ex- 
amined the role of teacher attachment in predicting interactions with young children (Howes, Galinsky, \& Kontos, 1998). Thus, based on both theory and empirical data, this may be a fruitful approach to understanding interactional quality. A second potential predictor of interactional quality is teachers' mental health. Both parenting and early childhood literature have documented the deleterious effects of depression on interactions with children (e.g., Cummings, Keller, \& Davies, 2005; Downey \& Coyne, 1990; Hamre \& Pianta, 2004; Kim-Cohen, Moffitt, Taylor, Pawlby, \& Caspi, 2005).

This research offers several important contributions to understanding career trajectories of early childhood professionals and the production of good quality care and education. We proposed and tested a model that considered how teacher characteristics such as education and motivation, along with intrinsic and extrinsic employment benefits are associated with child care quality and intention to stay in the profession. Four dimensions of teacher education were measured, and it appears that they function differently in the production of quality: total years of education consistently predicted compensation, while having a CDA consistently predicted observed quality. Child development specific coursework/training predicted compensation for teachers of infants and toddlers, but not for teachers of preschool aged children, and having a teaching certificate (often in preparation for working with older children) was not associated with observed quality or compensation. Compensation and motivations for child care work were tested simultaneously as predictors of intention to stay in the field; motivation was a robust predictor of intention to stay in the child care profession, while compensation was not significant.

A random sample of providers from a range of child care sectors (center-based infant/toddler and preschool teachers, for-profit and non-profit, those accepting children whose tuition is paid by subsidy and those that do not, licensed and legally license exempt centers, Early Head Start/Head Start partners) permitted us to test the models in a relatively heterogeneous sample, which supports generalizability of findings. Data were obtained from multiple informants, and maximum likelihood analysis estimated values of observational quality for survey respondents, permitting model testing for a survey sample of 964 and an observational sample of 223. This is a cost-effective way to leverage expensive data collection (observation) with relatively inexpensive data collection (survey) because observational data points are estimated for all survey respondents.

Limitations of this study point to future directions for research. A correlational design with all data collected at one point in time provides a snapshot of contemporaneous associations, but does not permit examination of associations over time. Examination of dynamics over time, for example, as opportunities or family circumstances change, may be especially important for understanding decisions to remain in the early childhood profession, or in a particular program. These data did not permit differentiation between choices to stay in the profession and choices to stay in a particular program, and this distinction is particularly important because Whitebook and Sakai (2004) noted that job turnover - leaving a program, but not leaving the child care field - differs from occupational turnover-leaving a program, and leaving the child care field. The present study examined intention to stay in the field, but not intention to stay in a particular program; it is possible that some participants intend to leave their programs for opportunities in the early childhood profession that offer better compensation and workplace supports, but this dimension of choice was not assessed in this study. Intention to leave also is distinct from actually leaving a program or the field. Child care income was examined as a continuous variable, but it is possible that if it is conceptualized in terms of "thresholds" - the amount of compensation that allows providers to afford to stay in the profession - relationships between compensation and retention may be better understood. Directly measuring perceptions of opportunities, such as advancement into administration, and opportunity costs may also illuminate dynamics of early childhood education career decisions.

Finally, the level of measurement of some of the variables did not permit estimation of fit indices for the model as a whole and the complexity of the model did not allow for all hypotheses to be tested simultaneously. It will be important for future research to examine paths we were not able to test. In addition, moderating influences of compensation on motivation in predicting observed quality and intention to stay is another potential strategy for understanding the complex interplay among these constructs. The current findings suggest that motivation directly predicts intention to stay in the field, with a policy implication that the most motivated providers would be good candidates for investments (e.g., the T.E.A.C.H program to increase provider education and wages). In addition, the consistent association between having a CDA and observed quality suggests that this credential should potentially be given more consideration in compensation decisions.

Qualitative research may be especially useful for investigating career trajectories of early childhood professionals, because it is a methodology well suited to examining how individuals construct meanings and use those meanings to make important choices. Qualitative research would also afford the potential to identify critical factors that have not been identified in this model, which is a reason why qualitative research is an effective tool for model building. 


\section{References}

Arnett, 1989 - J. Arnett, Caregivers in day-care centers: Does training matter?. Journal of Applied Developmental Psychology, 10 (1989), pp. $541-552$.

Barnett, 2002 - S. Barnett, Early childhood education, A. Molnar, Editor, School reform proposals: The research evidence, Educational Policy Research Unit, Tempe, AZ (2002), pp. 1-33.

Birch and Ladd, 1997 - S. H. Birch and G. W. Ladd, The teacher-child relationship and children's early school adjustment. Journal of School Psychology, 351 (1997), pp. 61-79.

Blau, 2000 - D. M. Blau, The production of quality in child-care centers: Another look. Applied Developmental Science, 43 (2000), pp. $136-148$.

Brewer, 1996 - D. J. Brewer, Career paths and quit decisions: Evidence from teaching. Journal of Labor Economics, 14 2 (1996), pp. $313-339$.

Buckingham and Coffman, 1999 - M. Buckingham and C. Coffman, First, break all the rules: What the world's greatest managers do differently, Simon \& Schuster, New York (1999).

Buell et al., 2002 - M. Buell, I. Pfister, and M. Gamel-McCormick, Caring for the caregiver: Early head start/family child care partnerships. In H. Fitzgerald, J. M. Love, H. H. Raikes, \& J. Robinson (Eds.), Infant Mental Health Journal Early Head Start Special Issue (2002), 213-230.

Burchinal et al., 2002 - M. Burchinal, D. Cryer, R. Clifford, and C. Howes, Caregiver training and classroom quality in child care centers. Applied Developmental Science, 61 (2002), pp. 2-11.

Center for Family Policy Research, 2002 - Center for Family Policy Research. (2002). Improving early education in Missouri: A workforce incentive project. (Policy Brief). University of Missouri-Columbia. Retrieved March 29, 2006, from http://web.missouri. edu/ umchescfprwww/winteachFeb\%202005.pdf

Center for the Child Care Workforce, 2002 - Center for the Child Care Workforce. (2002). Current data on child care salaries and benefits in the United States. Washington, DC. Retrieved October 6, 2004, from http://www.ccw.org/pubs/2002Compendium.pdf

Cleveland and Hyatt, 2002 - G. H. Cleveland and D. E. Hyatt, Child care workers' wages: New evidence on returns to education, experience, job tenure, and auspice. Journal of Population Economics, 153 (2002), pp. 575-597.

Cost Quality Outcomes Study Team, 1995 - Cost Quality Outcomes Study Team, Cost, quality, and child outcomes in child care centers: Key findings and recommendations. Young Children, 504 (1995), pp. 40-44.

Cummings et al., 2005 • E. M. Cummings, P. S. Keller, and P. T. Davies, Towards a process model of maternal and paternal depressive symptoms: Exploring multiple relations with child and family functioning. Journal of Child Psychology \& Psychiatry, 465 (2005), pp. 479-489.

Danes and Rettig, 1995 - S. M. Danes and K. D. Rettig, Economic adjustment strategies of farm men and women experiencing economic stress. Financial Counseling and Planning, 6 (1995), pp. 59-74.

De Wolff and Van IJzendoorn, 1997 - M. S. De Wolff and M. H. Van IJzendoorn, Sensitivity and attachment: A meta-analysis on parental antecedents of infant attachment. Child Development, 684 (1997), pp. 571-591.

Downey and Coyne, 1990 - G. Downey and J. C. Coyne, Children of depressed parents: An integrative review. Psychological Bulletin, 1081 (1990), pp. 50-76.

Fuller and Strath, 2001 - B. Fuller and A. Strath, The child-care and preschool workforce: Demographics, earnings, and unequal distribution. Educational Evaluation and Policy Analysis, 231 (2001), pp. 37-55.

Galinsky et al., $1994 \cdot$ E. Galinsky, C. Howes, S. Kontos, and M. Shinn, The study of children in family child care and relative care: Highlights of findings, Families and Work Institute, New York (1994).

Ghazvini and Mullis, 2002 - A. Ghazvini and R. L. Mullis, Center-based care for young children: Examining predictors of quality. The Journal of Genetic Psychology, 1631 (2002), pp. 112-125.

Grossmann et al., 1988 - K. Grossmann, E. Fremmer-Bombik, J. Rudolph, and K. E. Grossman, Maternal attachment representations as related to patterns of infant-mother attachment and maternal care during the first year, R. A. Hinde, J. Stevenson-Hinde, editors, Relationships within families, Oxford University Press, Oxford (1988).

Hamre and Pianta, 2004 - B. K. Hamre and R. C. Pianta, Self-reported depression in nonfamilial caregivers: Prevalence and associations with caregiver behavior in child-care settings. Early Childhood Research Quarterly, 192 (2004), pp. 297-318.

Harding, 1991 • J. Harding, A study of career intentions: 1990 intake diploma of teaching (early childhood) students. ERIC ED 343682 (1991).

Harms et al., 1998 - T. Harms, R. Clifford, and D. Cryer, The Early Childhood Environment Rating Scale, Revised, Teachers College Press, New York (1998).

Harms and Cryer, 1990 • T. Harms and D. Cryer, Infant/Toddler Environment Rating Scale, Teachers College Press, New York (1990).

Helburn, 1995 - S. W. Helburn, ed., Cost, quality, and child outcomes in child care centers: Technical report. Denver: University of Colorado at Denver, Department of Economics, Center for Research in Economic and Social Policy (1995).

Helburn and Howes, 1996 • S. W. Helburn and C. Howes, Child care cost and quality. Future of Children, 62 (1996), pp. 62-82.

Houkes et al., 2001 • I. Houkes, P. M. Janssen, J. de Jonge, and F. Nijhuis, Specific relationships between work characteristics and intrinsic work motivation, burnout and turnover intention: A multi-sample analysis. European Journal of Work and Organizational Psychology, 101 (2001), pp. 1-23.

Howes et al., 1998 - C. Howes, E. Galinsky, and S. Kontos, Child care caregiver sensitivity and attachment. Social Development, 7 (1998), pp. 25-36.

Howes et al., 1994 - C. Howes, C. E. Hamilton, and C. C. Matheson, Children's relationships with peers: Differential associations with aspects of the teacher-child relationship. Child Development, 65 (1994), pp. 253-263.

Jacobvitz et al., 1991 - D. Jacobvitz, E. Morgan, M. Kretchmar, and Y. Morgan, The transmission of mother-child boundary disturbances across three generations. Development and Psychopathology, 3 (1991), pp. 513-527. 
Kim-Cohen et al., 2005 - J. Kim-Cohen, T. E. Moffitt, A. Taylor, S. J. Pawlby, and A. Caspi, Maternal depression and children's antisocial behavior: Nature and nurture. Archives of General Psychiatry, 622 (2005), pp. 173-181.

Kontos et al., 1995 - S. Kontos, C. Howes, M. Shinn, and E. Galinsky, Quality in family child care and relative care, Teachers College Press, NY (1995).

Kontos et al., 1994 - S. Kontos, H. C. Hsu, and L. Dunn, Children's cognitive and social competence in child care centers and family day care homes. Journal of Applied Developmental Psychology, 15 (1994), pp. 387-411.

Love et al., 1996 - J. M. Love, P. Z. Schochet, and A. L. Mechstrom, Are they in any real danger? What research does - and doesn't - tell us about child care quality and children's well-being. Child care research and policy papers: Lessons from child care research funded by the Rockefeller Foundation. Princeton, NJ: Mathematica Policy Research, Inc. (1996). Retrieved April 4, 2005, from http:// www.mathematica-mpr.com/publications/PDFs/realdanger.pdf

Manlove and Guzell, 1997 - E. E. Manlove and J. R. Guzell, Intention to leave, anticipated reasons for leaving, and 12-month turnover of child care center staff. Early Childhood Research Quarterly, 122 (1997), pp. 145-167.

Murnane and Olsen, 1989 - R. J. Murnane and R. J. Olsen, The effects of salaries and opportunity costs on duration in teaching: Evidence from Michigan. The Review of Economics and Statistics, (1989), pp. 347-352.

Murnane and Olsen, $1990 \cdot$ R. J. Murnane and R. J. Olsen, The effects of salaries and opportunity costs on length of stay in teaching: Evidence from North Carolina. The Journal of Human Resources, 251 (1990), pp. 106-125.

Murray, 2000 - S. B. Murray, Getting paid in smiles: The gendering of child care work. Symbolic Interaction, 232 (2000), pp. 135-160.

NICHD Early Child Care Research Network, 2000 - NICHD Early Child Care Research Network, Characteristics and quality of care for toddlers and preschoolers. Applied Developmental Science, 43 (2000), pp. 116-135.

NICHD, 2002 - NICHD Early Child Care Research Network, Child-care structure, process, outcome: Direct and indirect effects of child care quality on young children's development. Psychological Science, 133 (2002), pp. 199-206.

Nelson, 2001 - J. A. Nelson, Why are early education and child care wages so low? A critical guide to common explanations. New York, NY: Foundation for Child Development Working Paper Series (2001). Retrieved April 1, 2005, from http://www.fcd-us.org/uploadDocs/WhyAreEarlyEducationandCareWages-Nelson.pdf

Olson, $2002 \cdot$ L. Olson, Starting early. Education Week, 17 (10-22-2002).

Pearce and Brooks, 2002 - D. Pearce and J. Brooks, The self-sufficiency standard for Nebraska, Nebraska Appleseed Center for Law in the Public Interest, Lincoln, NE (2002), Retrieved July 30, 2005, from http://www.sixstrategies.org/files/ACFD8.pdf

Phillips et al., 1991 - D. A. Phillips, C. Howes, and M. Whitebook, Child care as an adult work environment. Journal of Social Issues, 472 (1991), pp. 49-70.

Phillips et al., 2000 - D. A. Phillips, D. Mekos, S. Scarr, K. McCartney, and M. Abbott-Shim, Within and beyond the classroom door: Assessing quality in child care centers. Early Childhood Research Quarterly, 15 (2000), pp. 475-496.

Raikes et al., 2003 • H. Raikes, B. Wilcox, C. Peterson, S. Hegland, J. Atwater, and J. Summers, et al., Child care quality and workforce characteristics in four midwestern states, Midwest Child Care Research Consortium and The Gallup Organization, Lincoln, NE (2003), Retrieved June 2, 2004, from http://www.ccfl.unl.edu/projects/pdf/final 11-25-03.pdf

Rholes et al., 1995 W. S. Rholes, J. A. Simpson, and B. S. Blakely, Adult attachment styles and mothers' relationships with their young children. Personal Relationships, 2 (1995), pp. 35-54.

Sachs, 2000 J. Sachs, Inequities in early care and education: What is America buying? Journal of Education for Students Placed at Risk, 54 (2000), pp. 383-395.

Stinebrickner, 2001 - T. R. Stinebrickner, Compensation policies and teacher decisions. International Economic Review, 423 (2001), pp. 751-779.

Stremmel, 1991 - A. J. Stremmel, Predictors of intention to leave child care work. Early Childhood Research Quarterly, 6 (1991), pp. 285-298.

Van IJzendoorn, 1995 - M. H. Van IJzendoorn, Adult attachment representations, parental responsiveness, and infant attachment: A meta-analysis on the predictive validity of the Adult Attachment Interview. Psychological Bulletin, 1173 (1995), pp. 387-403.

Whitebook, 2002 - M. Whitebook, Working for worthy wages: The child care compensation movement, 1970-2001. New York, NY: Foundation for Child Development Working Paper Series (2002). Retrieved September 10, 2003, from http://repositories.cdlib.org/cgi/ viewcontent.cgi?article $=1000 \&$ context $=$ iir $/$ cscce

Whitebook, 2003 - M. Whitebook, Early education quality: Higher teacher qualifications for better learning environments - A review of the literature, Center for the Study of Child Care Employment, Berkeley, CA (2003). Retrieved April 4, 2005, from http://www.iir.berkeley. edu/cscce/pdf/teacher.pdf

Whitebook et al., 1990 - M. Whitebook, C. Howes, and D. Phillips, Who cares? Child care teachers and the quality of care in America. Final report of the national child care staffing study. Oakland, CA: Child Care Employee Project (1990). Retrieved March 6, 2006, from http:// www.ccw.org/pubs/whocares.pdf

Whitebook et al., 1998 - M. Whitebook, C. Howes, and D. Phillips, Worthy work, unlivable wages: The National Child Care Staffing Study, 1988-1997, Center for the Child Care Workforce, Washington, DC (1998). Retrieved July 20, 2005, from http://www.ccw.org/pubs/ worthywork.pdf

Whitebook et al., 1993 - M. Whitebook, D. Phillips, and C. Howes, National child care staffing study revisited: Four years in the life of centerbased child care, Child Care Employee Project, Oakland, CA (1993). Retrieved November 2, 2006, from http://www.ccw.org/pubs/ nccssrevisit.pdf

Whitebook and Sakai, $2004 \cdot$ M. Whitebook and L. Sakai, By a thread: How child care centers hold on to teachers, how teachers build lasting careers, Upjohn Institute, Kalamazoo, MI (2004).

Zaslow and Martinez-Beck, 2006 • M. Zaslow and I. Martinez-Beck, Early childhood professional development and children's successful transition to elementary school, Brooks, Baltimore, MD (2006). 